\title{
VIII. On radioactinium
}

\section{Otto Hahn Ph.D.}

To cite this article: Otto Hahn Ph.D. (1907) VIII. On radioactinium, Philosophical Magazine Series 6, 13:73, 165-180, DOI: 10.1080/14786440709463590

To link to this article: http://dx.doi.org/10.1080/14786440709463590

曲 Published online: 16 Apr 2009.

Submit your article to this journal $\pi$

LII Article views: 6

Q View related articles $\asymp$

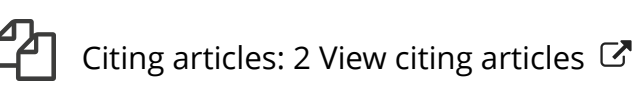


VIII. On Radioactinizm. By Отто $\mathrm{H}_{\mathrm{AHN}}$, Ph.D.**

TN a previous paper $\dagger \mathrm{I}$ gave a brief account of the 1 methods of separation and the radioactive properties of a new product of actinium, which was called "radioactinium," as its position in the disintegration series of actinium is the same as that of radiothorium in the thorium series.

The object of the present paper is to consider in more detail the properties of radioactinium, and also the experimental and theoretical curves, which throw light on its properties as the intermediate product between actinium and actinium $\mathrm{X}$.

\section{Preparation of Radioactinitum.}

The experiments on radioactinium were made both with actinium of Debierne (kindly lent to me by Sir William Ramsay) and actinium (emanium) of Giesel. Again, as in previous cases, no differences in the radioactive behaviour of the two substances could be observed $\rightarrow$ a result which proves beyond question the identity of the radioactive constituents of the two preparations.

On dissolving in hydrochloric acid an actinium preparation in the form of a fine powder which has previously been heated, the resulting solution is generally not clear. A small portion, depending on the strength and nature of the acid and on the active preparation employed, remains undissolved.

If a small quantity of the filtrate is evaporated to dryness and tested from time to time in an electroscope, it is soon found that the activity continues to increase for a long time. The activity curves first obtained in this way were not very regular, but they showed a different shape from that to be expected, if the rise in activity were only due to the production of actinium $\mathrm{X}$ and its successive products.

In addition, the change in activity of the insoluble part was very different from the well-known bebaviour of actinium $X$ or of a mixture of actinium and a surplus of actinium $X$.

In some cases, the activity of the filter, instead of decreasing remained nearly constant or actually increased. This result was very puzzling, as the activity of the filtrate was also increasing at the same time.

All these results were quite unexpected, and at the time no reasonable explanation suggested itself.

In order to find out whether physical conditions, such as diffusion, moisture, \&c., were in any way responsible for this

* Communicated by the Author.

+ 'Nature, May 1906; Ber. xxxix. p. 1605. 
anomalous behaviour, a large number of experiments were undertaken to test the variation of activity under different conditions and with different methods of preparation.

As the general result it was seen, that the undissolved part of the preparation contained a new radioactive product. If, in addition, actininm $X$ also remained in the insoluble portion, the activity of the filter was nearly constant for some time, and then decayed slowly, finally diminishing according to an exponential law with a period of abont 20 days.

If there was no actinium $\mathrm{X}$ in the insoluble part, the activity of the latter at first inereased, reached a maximum after abont two or three weeks, and later decayed with a period of about 20 days.

This product with a decay period of about 20 days was later called "radioactinium," when its position in the actinimu series had been settled.

The method of preparation of this new product, previously described, was not very satisfactory, and generally gave in mixture of the whole series of actinium products together with a surplus of radioactinium.

The following two methods proved much more satisfactory and rendered it possible to obtain the product radioactinium free, or at least, nearly free, from actinium and actinium X.

Actinium, which had been standing for a few months in solution in order to reach the equilibrium state of activity, was precipitated several times with ammonia. By this method Godlewski and, independently, Giesel have shown that actinium $X$ remains in solution, while actinium itself remains in the precipitate. The precipitation had to be repeated several times to make the separation of actinium $\mathrm{X}$ as complete as possible.

The actinium precipitate is dissolved in hydrochloric acid, and to the acid solution is added a very little sodium thiosulphate solution. The latter is decomposed by the acid, and amorphous sulphur soon appears. The sulphur in the cold solution is allowed to settle down for some time and is then filtered and washed. The surplus is then burnt in a porcelain crucible. An appreciable residue is always observed because some of the rare earths, like thorium, are precipitated with the sulphur.

This residue shows considerable activity, depending of course on the amount of actinium taken for the experinient. The activity increases to about twice the initial strength and then decays slowly, finally diminishing according to an exponential law with a perior of abont 20 days. 
The other method, which proved satisfactory for the separation of radioactinium, is described already in my paper on "The Ionization Ranges of Actinium "* A small quantity of ammonia is added to an actinium solution in radioactive equilibrium in amount sufficient to produce only a partial precipitation. The ammonia filtrate is redissolved and part again precipitated. After repeating this process several times, all the actininm $X$ and the greatest part of the actinium remain in solution, while the radioactinium remains in the precipitate. The latter is then treated in the same manner as the sulphur precipitate deseribed above.

The methods of separation of radioactinium, which we have outlined, are not altogether as satisfactory or reliable as could be wished. In some cases a very complete separation is obtained, but in others some actinium is carried down or other difficulties are encountered. The right conditions are not always easily found, but, in general, the separation can be effected by the methods described above.

Some recent experiments of Levin seem to show that radioactinium can also be separated to some extent by electrolysis.

\section{Railoactive Properties of Radioactinium. a. Nature of the Radiations.}

Radioactinium emits $\alpha$ rays. In the previous paper $\dagger$ I described the methods of preparing a thin film of this radioactive product, sufficiently active for the determination of the range of its $\alpha$ particles by the electric method. It was shown that freshly prepared radioactinium emits one homogeneous type of a rays, which are able to ionize the air for a distance of $4.8 \mathrm{cms}$. at ordinary pressure and temperature.

While newly prepared radioactinium always shows a very considerable $\alpha$ ray activity, the $\beta$ ray effect at first is very weak, and is probahly due to the presence of a slight amount of actinium B. This is in accordance with the results of Levin obtained in Rutherford's laboratory, for he has shown that actinium $B$ is the only product of actinium which emits $\beta$ rays.

A small amount of actinium emanation is also present. Since actinium $X$ is the direct parent of the emanation, the amount of emanation in the preparation is a measure of the amount of actinium present:

As we shall prove later in this paper, actinium $\mathrm{X}$ is formed by the radioactinium : it is therefore very difficult to obtain a 
radioactinium preparation completely free from emanation, but a preparation can easily be obtained which initially shows only a very small emanating power compared with the value observed two or three weeks later.

The amount of emanation and of $\beta$ ray activity observed rise proportionally, since actinium $B$ which emits the $\beta$ rays is a product of the emanation.

The $\alpha$ and especially the $\beta$ ray activity of the radioactinium preparation increase rapidly for a week or more, and then more slowly as the maximum is reached (see figs. 1 \& 2, pp. $173 \& 175$ ). The activity measured by the a rays reaches a maximum slightly earlier than the activity measured by the $\beta$ rays or by the amount of emanation present.

\section{b. Decay Period of Radioactinium.}

It was very soon recognized that the period of the decay was not the $10 \cdot 2$ day period of actinium $X$ but considerably slower. The activity, whether measured by the $\alpha$ or $\beta$ rays or the amount of emanation present, finally decays according to an exponential law. It generally does not decay quite to zero, but a small residual activity of a few percent. was observed, indicating that the preparation contained small traces of actinium. By using actinium preparations carefully freed from radium, the possibility of this residual activity being due to radium was excluded.

After subtracting the small residual activity, the exponential nature of the decay curve was easily to be observed. The following values of the decay constant $\lambda$ (see.-1) were found for several decay curves of radioactinium, which bad been prepared by different methods and using both the actinium of Debierne and the actinium of Giesel :-

$$
\begin{array}{cc} 
& 0.425 \times 10^{-6} \\
& 0.413 \times 10^{-6} \\
& 0.399 \times 10^{-6} \\
& 0.407 \times 10^{-6} \\
& 0.412 \times 10^{-6} \\
& \\
\text { Average } & 0.411 \times 10^{-6}
\end{array}
$$

From this it follows that the time for radioactinium to be half transformed is $1.68 \times 10^{6}$ secs. or 19.5 davs.

This value is a little lower than the value of 20 days, which I stated in my first paper on the subject. The period 19.5 days may still be slightly in error. Further measurements are in progress to determine the period with more accuracy. 
For an example the following table gives the experimental (I.) and theoretical (II.) values of the activity; II. supposing the period is 19.5 days. This only refers to the part of the decay curves obtained about one month and a half after the preparation of the radioactinium, when the decay is exponential. The numbers at I. are corrected by subtracting a small constant residual activity. In both cases, the value after $19 \cdot 5$ days is taken as $50 \cdot 0$.

\begin{tabular}{|c|c|c|}
\hline Time in days. & $\begin{array}{c}\text { I. } \\
\text { Observed. }\end{array}$ & $\begin{array}{c}\text { II. } \\
\text { Calculated. }\end{array}$ \\
\hline $0 \ldots \ldots \ldots \ldots$ & $98 \cdot 2$ & 100 \\
\hline 5 …….......... & 84.8 & 838 \\
\hline $8 \ldots$ & $77: 2$ & $75 \cdot 1$ \\
\hline $195 \ldots \ldots \ldots$ & $50 \cdot 0$ & 500 \\
\hline $45 \quad \ldots \ldots \ldots \ldots \ldots$ & $21 \cdot 2$ & 200 \\
\hline $62 \ldots \ldots \ldots \ldots$ & $11 \cdot 4$ & $11 \cdot 0$ \\
\hline $67 \ldots$ & $9 \cdot 30$ & 925 \\
\hline 81) & 585 & $5 \cdot 80$ \\
\hline 89 & $4 \cdot 25$ & $4 \cdot 25$ \\
\hline 109 & $2 \cdot 45$ & $2 \cdot 1$ \\
\hline
\end{tabular}

Thus over an interval of nearly four months the numbers are in a satisfactory agreement, showing that the decay is exponential with the period stated above.

\section{c. Position of Radioactinium in the Radioactive Series.}

The following experiments were made to throw light on the position of radioactinium in the actinium series. The radioactinium was prepared after one of the methods previonsly described and was tested on the filter. It exhibited the characteristic variation of $\alpha$ and $\beta$ ray activity, viz. a rapid rise measured by the $\beta$ rays and a more gradual rise measured by the $\alpha$ rays. The maximum value was reached after two and a half weeks. Shortly after reaching the maximum, the filter containing the sodium thiosulphate precipitate was burnt in a porcelain crucible and a solid white residue remained, which probably consisted in part of thorium oxide and other rare earths.

This residue, which weighed only a few milligrams, was then treated with strong nitric acid. A part of the residue remained undissolved. After dilution and filtration, the filtrate was precipitated with ammonia and left standing for a short time. A very small quantity of a colourless jelly-like precipitate appeared and was filtered through the first filter, which contained the trace of undissolved residue. The 
ammonia filtrate was evaporated, heated and tested in the electroscope, the filter was burnt, and the small residue also tested in a similar way.

Both preparations showed considerable $\alpha$ ray activity, while the filter also showed considerable $\beta$ ray activity.

The activity of these two preparations raried, however. in a very different way. The activity of the filter increased in exactly the same way as that of the initial radioactinium, when first prepared; the activity of the filtrate, however, steadily decreased according to an exponential law with a period of about 11 days.

There is no doubt that this decaying product was actininm $\mathrm{X}$, for which Godlewski found a period of 10.2 days.

On repeating the above-described experiment, the activity of the ammonia filtrite was found to decar to balf value in about 12 days and then slightly slower, indicating that the product consisted mainly of actinium $\mathrm{X}$ but also contained a little radioactinium.

For comparison, some actinium $\mathrm{X}$ was now prepared after the method of Godlewski atd of Giesel from actinitum solution itself and not from radioactinium. On account of the great number of other preparations under investigation, care could not be taken to avoid slight irregularities of the activity arising from the effect of moisture and other influences on the actinium $X$. The period found for actinium $X$ was therefore not very accurate; 11 days, or even a little longer, was found instead of 10.2 days, as found by Godlewski. It is intended at an early date to repent these experiments in order to determine with greater accuracy the decay and rise curves of the products actinium, radioactinium, and actinium $\mathrm{X}$.

The separation of actinium $\mathbf{X}$ from decaying radioactinium, which originally was almost entirely free from actinium $X$, shows clearly that actinium $\mathrm{X}$ is continuously produced by radioactinium. This is confirmed by the fact that old radioactinium, from which the actinium $\mathrm{X}$ has been removed, again increases in activity in exactly the same way as a newly prepared specimen. This increase of activity is due to the formation of actinium $X$ and its successive products; after reaching a maximum, the actinium $\mathrm{X}$ and radioactinium are in approximate radionctive equilibrium, and the activity finallydecays according to the period of radioactininm.

In order to prove this connexion beyond question, the ionization curves of the a particles of radioactinium were determined at different intervals after preparation.

In my paper on "The Ionization Ranges of the a Particles of Actinium," I described the methods of preparing a thin 
film of the active substance and gave the ionization curves obtained with it.

The success was complete. Immediately after preparation of the radioactinium the $\alpha$ rays were found to be homogeneous and had a range of $4.8 \mathrm{cms}$. This result showed that only one $\alpha$ ray product, viz. radioactinium, was present.

Progressive measurements showed the gradual entrance of new kinds of $\alpha$ rays, the most penetrating of which were shown to be due to actinium $X$.

If the actinium $X$ was separated the ionization curves: showed exactly the same variation with time as before.

\section{d. Comparison of the Evverimental with the Theoretical Curres. (1) \& Ray Curves.}

Knowing the period of radioactinium and its connexion with the other actinium products, it is not difficult to deduce theoretically the rise and decay curves, measured by the $\alpha$ and $\beta$ rays, that should bo exhibited by radioactinium.

We must remember that Ra Act. is the parent of Act. X, which in turn is transformed through the stages emanation, actinium $A$, and actinium $B$.

Let $\lambda_{1}, \lambda_{2}$ be the constants of transformation of radioactinium and actinium $X$ respectively.

Let $P$ and $Q$ be the number of atoms of radionctinium and actinium $X$ respectively existing at any time $t$ after the preparation of the radionctinium. Then it is known from Rutherford's theory of the successive changes * that

$$
\begin{aligned}
& \mathrm{P}=n \cdot e^{-\lambda_{1} t}, \\
& \mathrm{Q}=\frac{n \cdot \lambda_{1}}{\lambda_{1}-\lambda_{2}}\left(e^{-\lambda_{2} t}-e^{-\lambda_{1} t}\right),
\end{aligned}
$$

where $n$ is the number of atoms of radioactinitum initially present.

Now the $\alpha$ ray activity of the radioactinium some time after preparation is due to radioactinium, actinium $\mathrm{X}$, the emanation, and actinium $B$. The period of actinium $\mathrm{X}$ is $10 \cdot 2$ days, of the emanation 3.9 secs., of actinium A 36 minutes, and of actinium B 2 minutes. The changes following actinium $X$ are thus very rapid compared with actinium $X$ itself, and we may, for the purpose of calculation, assume without sensible error that the changes succeeding actinium $X$ are instantaneous. We may therefore include the activity due to these products with that of actinium $\mathrm{X}$.

Now the activity $I_{t}$ (measured by the electrical metholl) of * Rutberford, 'Radioactivity', ?nd edition, p. 399. 
the preparation of radioactinium at any time $t$ is proportional to

$$
\lambda_{1} \mathrm{P}+\lambda_{i} \cdot \lambda_{2} \mathrm{Q},
$$

where $k$ is a constant, which may be defined as the ratio of the jonization resulting from the disintegration of an atom of actinium $\mathbf{X}$ through the stages emanation and actinium B to that resulting from the disintegration of an atom of radioactinium.

If $I_{0}$ is the activity of the radionctinium immediately after preparation,

$$
\begin{aligned}
\overline{\mathrm{I}}_{t} & =\frac{\lambda_{1} \mathrm{P}+k \cdot \lambda_{2} \mathrm{Q}}{\overline{\mathrm{I}}_{11} \cdot n} \\
& =e^{-\lambda_{1} t}+\frac{l_{\lambda_{2}}}{\lambda_{\mathrm{L}}-\lambda_{2}}\left(e^{-\lambda_{2} t}-e^{-\lambda_{1} t}\right) .
\end{aligned}
$$

This equation expresses the variation of activity of radioactinium, measured by the a rays.

It now remains to form an idea of the magnitnde of the constant $l$. If each of the $\alpha$ ray products of actinium emitted a particles which produced exactly the same ionization in the surrounding gas, the value of $k$ should be 3 . This is obviously the case, since the ionization dne to the emanation and actinium $\mathrm{B}$ is included with actinium $\mathrm{X}$. The ionization, however, is not the same for all the actinium prodlucts, for I have shown that the ranges of ionization of the products radioactinium, actinium $\mathrm{X}$, emanation, and actinium $\mathrm{B}$ are $4 \cdot 8$, $6 \cdot 55,5 \cdot 8$, and $5.50 \mathrm{cms}$. respectively. With a thin film of radioactive matter, the ionization due to each a particle escaping into the air should be approximately proportional to the range in air.

This relation has been shown by Boltwood * to hold closely for radium preparations. Consequently, if the measurements are made with a very thin film of radioactinium and under such conditions that the $\propto$ particles are completely absorbed between the plates of the testing vessel, the value of $k$ should be $6 \cdot 55+\frac{5 \cdot 8+5 \cdot 50}{4 \cdot 8}=3 \cdot 72$, instead of 3 .

If. however, a comparatively thick layer of radioactinium is employed, the value of $k$ should be still greater. This follows from the fact that the a particles of greatest range in air not only produce more ionization in the gas but, in audition, more escape into the gas, since they can reach the surface trom a greater depth of radioactive matter than the a particles of smaller range.

* Boltwood, A mer. Journ. Sci. June 1906. 
The above theory depends on the assumption that all of the radioactive products are completely retained in the radioactive matter. In practice, however, the preparations always lose a portion of their emanation dy diffusing into the air. In consequence of this, the activity due to the succeeding product actinium $B$ is less than the theoretical ralue if no emanation eseaped. For a thin film of radioactinium we should consequently expect a value of $k$ less than 3.72 , and this value will be variable within limits depending upon the emanating power of the compound.

Fig. 1 .

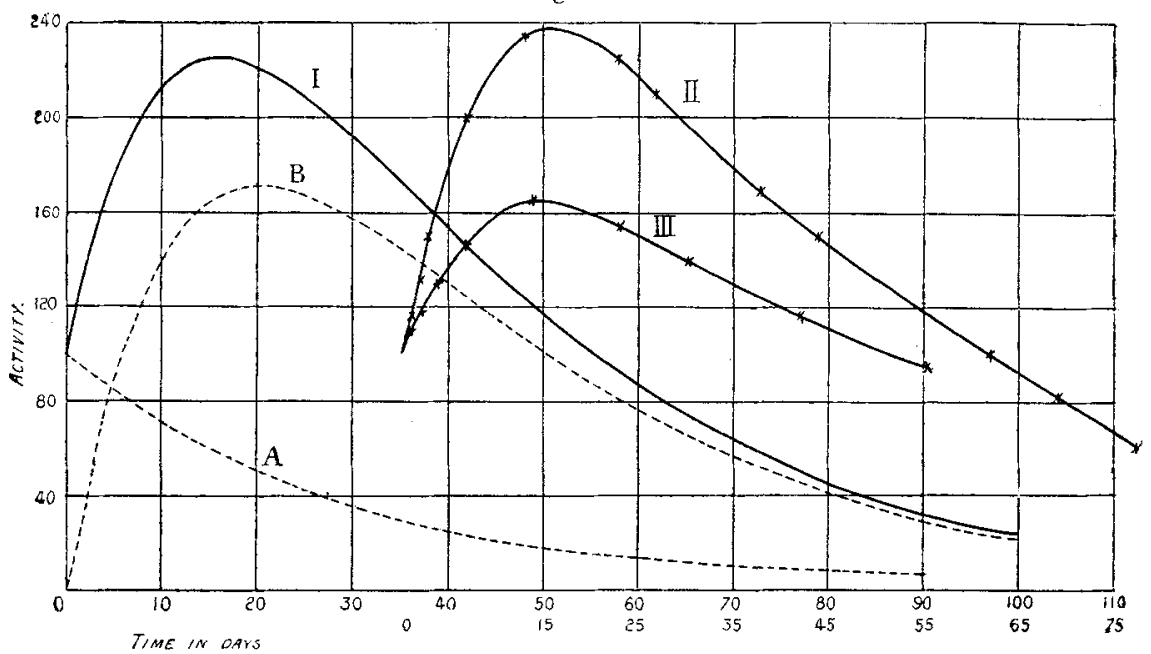

The theoretical curve is drawn in fig. 1, Curve I., the initial activity due to radioactinium being taken as 100 . The shape of the curve agrees fairly closely with the experimental curve (Curve II.) plotted in the same way. The maximum ordinate of the theoretical curve is slightly less than the experimental value, showing that the value of $k$ is slightly greater than $3 \cdot 5$.

The theoretical curve can be simply analysed into its components. The exponential curve A shows the activity at any time due to radioactinium itself. The difference curve $\mathbf{B}$ shows the activity at any time due to actinium $X$ and its succeeding products.

Curve III. is another example of an experimental curve, which was obtained under conditions where the radioactinium probably contained some actinium and actinium $\mathbf{X}$.

The maximum of the theoretical curve (Curve I.) is reached 
after about 17 days, and the maximum of the experimental Curve II. is reached aiter the same interval. In Curve III. the maximum is reached in 14 days. 'The earlier occurrence of the maximum is to be expected if any sensible amount of actinium $X$ is present initially with the radioactinium. In this case not only is the maximum reached earlier, but the increase of activity is also smaller. This is seen to be the case in the experiments, for the activity of Curve II. rises to more than twice its initial value, while in Curve III. it rises to only about $1 \cdot 5$ times.

The a ray curves are thus in very satisfactory agreement with the theory. The agreement of Curve II. with the theoretical curve is especially good over the whole range of obseryations. The theoretical activity ultimately decays exponentially with the period of radioactinium-a result in entire harmony with the experiments discussed earlier in the paper.

The results obtained are thus in complete accordance with the view that radioactinium is an $\alpha$ ray product of period $19 \cdot 5$ days, which is transformed into actinium $X$ of period $10 \cdot 2$ days.

\section{(2) B Ray Curves.}

Radioactinium emits only $\alpha$ rays, and Levin has shown that the $\beta$ ray activity of any preparation of actinium arises only from the product actinium $B$. Disregarding a small time-lag, the amount of actinium B present is proportional t.o the amount of the parent product actinium $X$. But we have seen that the number of atoms $Q$ of actinium $\mathrm{X}$ present at any time is given by the formula

$$
\mathrm{Q}=\frac{n \lambda_{1}}{\lambda_{1}-\lambda_{2}}\left(e^{-\lambda_{2} t}-e^{-\lambda_{1} t}\right) \text {. }
$$

The $\beta$ ray activity of the radioactinium preparation is proportional at any time to the value of $Q$.

The theoretical curve for the variation of the $\beta$ ray activity of radioactinium is shown in fig. 2. The activity starts from zero, rises to a maximum after 20 days, and ultimately decays exponentially with the period of radioactinium, viz., $19 \cdot 5$ days. The experimental observations are shown by crosses on the curve and are seen to lie closely on the theoretical curve. The observations of this particular preparation were not continued after 30 days, as the preparation was utilized for a further chemical examination. Other observations have shown that the $\beta$ ray activity ultimately decays exponentially with 
the same period as the $\alpha$ ray activity, viz., with the period of 19.5 days. This is in agreement with the theory.

Fig. 2.

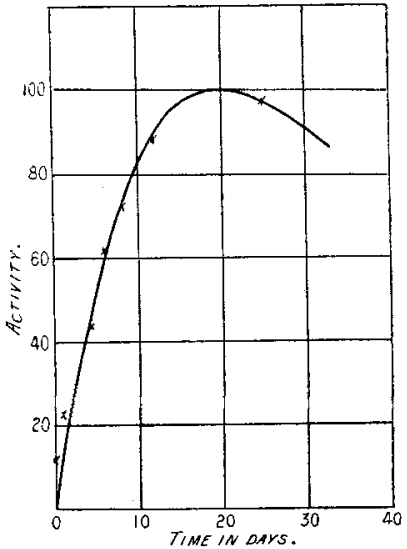

Connexion of Radioactinium with Actinium.

It is now necessary to consider the connexion of the new product radioactinium with actinium itself.

Until recently, it was generally believed that actinium was the direct parent of actininm $X$. The intermediate product radioactinium had been overlooked. It was believed that actinium itself did not emit any rays, and that therefore by separation of actinium $\mathrm{X}$ it could be nearly completely freed from activity. This, however, is not correct.

M. Levin*, working in the same laboratory as the writer, determined with great accuracy the residual $\alpha$ ray and $\beta$ ray activity of actinium after actinium $\mathrm{X}$ had been completely separated. By the well-known method of precipitation with ammonia, by continued precipitations he was able to reduce the emanating power of an actinium solution to one thousandth of its initial value. The separation of actinium $X$ was very complete, but his actinium was still quite active. It always howed a strong $\alpha$ ray activity not less than about 22-25 per cent. of its initial value. Levin states that this activity is due to the presence of radioactinium which is not separated from actinium by means of ammonia. This conclusion is in full harmony with the observations of the writer.

In order to obtain actinium inactive, the radioactinium as well as actinium has to be separated. It is difficult to effect a complete separation of the radioactinium, when employing 
very small quantities of working material. But the writer finally succeeded in reducing the a ray activity to $2 \cdot 5$ per cent. of the initial value. The method employed to separate the radioactinium and actinium $\mathrm{X}$ from actinium was as follows:-

Actinium solution in equilibrium was precipitated several times with ammonia. Care has to be taken not to filter too early, as it takes a considerable time for the actinium to come out *. By this method, actinium X remains in the filtrates, actinium and radioactinium remain on the filter. The filter was again dissolved in dilute hydrochloric acid, and to the solution a little ammonia was added in order to weaken the free acid. To the weak acid solution a small quantity of dilute sodium-thiosulphate solution was added at ordinary temperature. The small sulphur precipitate carries the radioactinium down; actinium remains in solution. If the filtrate was still decidedly active, the process of precipitating traces of amorphous sulphur was repeated. This method of separation works very satisfactorily. In order to avoid the presence of sodium sulphite in the actinium solution, the separation may be carried out in a different way by fractional precipitation with ammonia. The first part always contains an excess of radioactinium, while the actinium is concentrated with the later parts. But this method does not effect a very rapid separation, and one sulphur precipitate is in many cases more effective than many careful ammonia precipitations.

The activity of the actinium obtained in this way is very small. The activity only increases slightly in the course of the first few days, but then rises more rapidly for over a month and reaches nearly a constant value after four months (compare (urve II. fig. 3, p. 177). It is of interest to compare the experimental curve of recovery of activity with that to be expected from theory. As before, the chinges following actinium $\mathrm{X}$ may be supposed without any sensible orror to be simultaneous. Actinium changes so slowly compared with its products that we may suppose that it breaks up at a constant rate, giving rise to radioactinium which in turn is transformed into actinium $X$. Since actinium itself is rayless, the curve of recovery of activity is complementary to the eurve showing the decay of activity of radioactinium and actinium $X$ initially in radioactive equilibrium (see) Rutherford, 'Radioactivity,' vol. ii. p. 336).

Let $P_{0}, Q_{0}$ represent the number of atoms of radioactinium and actinium $X$ respectively present in a stage of equilibrium. 
If $\lambda_{1}$ and $\lambda_{2}$ respectively are the constants of change of these substances, then

$$
\lambda_{1} \mathrm{P}_{0}=\lambda_{2} \mathrm{Q}_{0} .
$$

Let $\mathrm{P}+\mathrm{Q}$ represent the number of atoms of radioactinium and actinium $\mathrm{X}$ present at any time $t$ after the actinium is removed. Then

$$
\begin{aligned}
& \mathrm{P}=\mathrm{P}_{0} \cdot e^{-\lambda_{1} t}, \\
& \mathrm{Q}=\frac{\mathrm{Q}_{0}}{\lambda_{2}-\lambda_{1}}\left(\lambda_{2} \cdot e^{-\lambda_{1} t}-\lambda_{1} \cdot e^{-\lambda_{2} t}\right)^{*}
\end{aligned}
$$

The activity $\mathrm{I}_{t}$ at any time $t$ is proportional to

$$
\lambda_{1} \mathrm{P}+k \cdot \lambda_{2} \mathrm{Q}
$$

where $k$ is a constant. If $I_{20}$ is the initial activity,

$$
\mathrm{I}=\frac{\lambda_{1} \mathrm{P}+k \cdot \lambda_{2} \mathrm{Q}}{\mathrm{I}_{\mathrm{i}} \mathrm{P}_{0}+k \cdot \lambda_{2} \mathrm{Q}_{0}}=\frac{\stackrel{\mathrm{P}}{\mathrm{P}_{0}}+\frac{k \mathrm{Q}}{\mathrm{Q}_{0}}}{1+k} .
$$

The rise-curve is complementary to this, and consequently $\frac{\text { Activity at any time } t}{\text { Final activity }}=1-\frac{\mathrm{I}_{t}}{\mathrm{I}_{0}}$,

$$
=1-\frac{\left[e^{-\lambda_{1} t}+\frac{k}{\lambda_{2}-\lambda_{1}}\left(\lambda_{2} \cdot e^{-\lambda_{1} t}-\lambda_{1} \cdot e^{-\lambda_{2} t}\right)\right]}{1+k}
$$

Fig. 3.

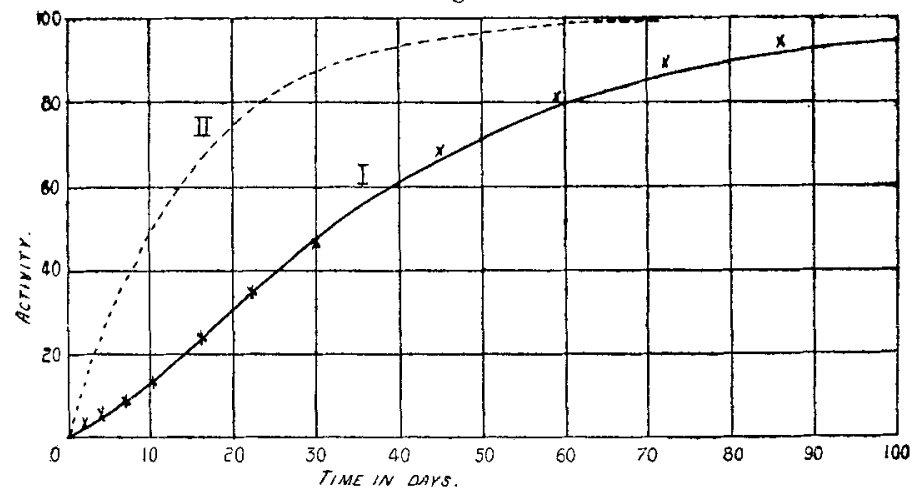

Taking the periods of radioactinium and actinium $\mathrm{X}$ as $19 \cdot 5$ days and $10 \cdot 2$ days respectively, the theoretical curve is given in fig. 3, Curve $I$., the maximum activity being taken as 100 . The value of $k$ is assumed to be $3 \cdot 5$ - the same value

* These equations are given in 'Radioactivity,' vol. ii. p. 334. Phil. Mag. S. 6. Vol. 13. No. 73. Jan. 1907. 
as previously employed. The experimental values are shown by crosses on Curve I. ; the agreement between the theory and experiment is clearly seen. The initial activity, experimentally found, is 2.4 per cent.; after about 4 days the experimental values lie closely on the curve for about one month. After that time, the experimental values lie somewhat above the theoretical curve.

We previously pointed out that the value of $k$ is uncertain between limits, and varies for different experiments. Taking this factor into consideration, there is an excellent agreement between theory and experiment. For comparison, a curve is drawn in fig. 3 (Curve II.), which represents the rise-curve for actinium, if the latter produced actinium $\mathrm{X}$ directly, as was generally believed before the separation of radioactinium. The difference between the two curves is striking. While in Curve II. the activity has reached half of its final value after $10 \cdot 2$ days, the experimental Curve I. shows that more than 30 days are required for the activity of actinium to reach half of its maximum value.

We therefore see conclusively that the rise-curve for actinium is not complementary to the decay-curve of actinium $\mathrm{X}$, but behaves just as it should do theoretically under the assumption that radioactinium is a product between actinium and actinium $\mathrm{X}$.

\section{Other Properties of Radionctinidm.}

It is not possible to make any definite statement in regard to the chemical properties of radioactinium. The varions methods employed for its separation are very similar in nature, and cannot be considered to be definite chemical reactions in the ordinary sense.

It is well known that barium sulphate possesses the property of dragging down many radioactive products from a solution, and the methods used for the separation of radioactinium appear to depend on a similar principle. A satisfactory explanation of these facts has not so far been given. It must not be forgotten that, with the exception of such slowlychanging substances as radiolead, polonium, and radiothorium, most of the products of the various radioelements exist in almost infinitesimal proportion mixed with the parent matter.

Methods of separation, similar in principle to those employed in the case of radioactinium, ought never be taken as a means of description of these products, and any system of classification based on such facts is liable to be very erroneous *

* A discussion of these points for the case of actinium has been given too by Godlewski, Jahrb. d. Rad. u. Elektr. vol. ii. 1906. 
The peculiarities of such reactions are clearly brought out when varying quantities of precipitating material are used. For example, the following experiments were made:-An excess of sulphuric acid was added to an actinium solution in equilibrium. The clear dilute acid solution was divided into three portions.

Portion 1 was presipitated with $0 \cdot 1$ c.c. of barium chloride. Portion 2

Portion 3

$" \quad " \quad$,
1 c.c." about 10 c.c. of barium chloride.

The three solutions were treated in exactly the same manner. In order to determine the amount of active matter removed by the barium precipitates, it was not satisfactory to determine the activity of the precipitates themselves, as the amount of inactive matter contained in the three portions varied in the ratio of about $1: 100$. Recourse was had in the filtrates, from which thin films of active matter could be obtained whose activity could be compared quantitatively. For this purpose the acid filtrates were neutralized with ammonia, then the solutions evaporated to dryness in equal vessels and the ammonia-salts driven off by heating. Small films of the active matter were left behind, and the $a$ ray activity of these thin layers of material could easily be compared under identical conditions.

It was found that the activities of the filtrates varied in the following manner, the activity of portion 1 being taken as $100:-$

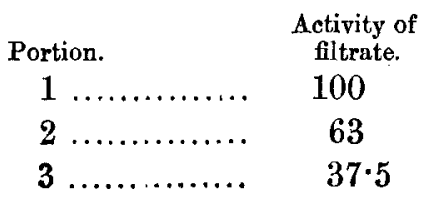

The result thus shows that the filtrates get weaker the more barium has been precipitated as sulphate. For this special case the activities were approximately 1, 2, 3 for quantities $1,10,100$.

This is in general agreement with the results of other observers for other products, and again shows conclusively that the reactions are not chemical in nature.

Other properties of radioactinium have not so far been studied in detail.

Like radiothorium, radioactinium is not volatilized by means of an ordinary blowpipe at a temperature where actinium $A$ and actinium $B$ are freely volatile. Still higher 
temperatures may possibly effect a separation of radioactinium from actinium, but this point has not yet been examined.

For convenience, the disintegration series of actinium is given, together with the period of the products and the radiations they emit :-

\begin{tabular}{|c|c|c|}
\hline Product. & $\begin{array}{l}\text { Time to be half } \\
\text { transformed. }\end{array}$ & Radiation. \\
\hline Actinium... & $?$ & Rayless. \\
\hline Radioactinium ...... & about $19 \cdot 5$ days. & $a$ rays. \\
\hline$\underset{1}{\text { Actinium } \mathrm{X}} \ldots \ldots \ldots$ & $10 \cdot 2$ days. & $a "$ \\
\hline Emanation ............. & $3 \cdot 9$ secs. & $a$ \\
\hline Actinium $A\}$ active & 36 mins. & Rayless. \\
\hline Actinium B J deposit. & 2 mins. & $a, \beta, \& \gamma$ rays. \\
\hline
\end{tabular}

Summary of Results.

The results brought out in this paper are chiefly summarized below :-

(1) A new product called "radioactinium" exists in the disintegration series of actinium. This new product is produced directly from actinium and is the direct parent of actinium $\mathrm{X}$.

(2) The transformation of actinium into radioactinium is rayless.

(3) Radioactinium emits only $a$ rays and is half transformed in about 19.5 days.

(4) The methods of separation employed for the isolation of radioactinium throw no definite light on its properties.

The present research was done at the McGill Physics Building at Montreal (Canada). Now that my visit to Montreal has come to an end, I record with much pleasure my gratitude to Prof. Rutherford for his kindness, interest, and ready help during the whole of my stay at the McGill University.

Berlin: Chemical Institute of the University. 